\title{
A survey on computational methods in discovering protein inhibitors of SARS-CoV-2
}

\author{
Qiaoming Liu (D), Jun Wan (1D) and Guohua Wang
}

Corresponding author: Jua Wan. E-mail: junwan@iu.edu; Guohua Wang. E-mail: ghwang@nefu.edu.cn

\begin{abstract}
The outbreak of acute respiratory disease in 2019, namely Coronavirus Disease-2019 (COVID-19), has become an unprecedented healthcare crisis. To mitigate the pandemic, there are a lot of collective and multidisciplinary efforts in facilitating the rapid discovery of protein inhibitors or drugs against COVID-19. Although many computational methods to predict protein inhibitors have been developed [1-5], few systematic reviews on these methods have been published. Here, we provide a comprehensive overview of the existing methods to discover potential inhibitors of COVID-19 virus, so-called severe acute respiratory syndrome coronavirus 2 (SARS-CoV-2). First, we briefly categorize and describe computational approaches by the basic algorithms involved in. Then we review the related biological datasets used in such predictions. Furthermore, we emphatically discuss current knowledge on SARS-CoV-2 inhibitors with the latest findings and development of computational methods in uncovering protein inhibitors against COVID-19.
\end{abstract}

Key words: COVID-19; SARS-CoV-2; therapeutics; antiviral drugs; inhibitors; computer-aid drug design

\section{Introduction}

Since the first instance of the new coronavirus, Coronavirus Disease-2019 (COVID-19), was uncovered in Hubei Province, China in December 2019, there have been approximately 18 months after turning the local pandemic into the global one. As of 8 June 2021, a total of about 174 million people were infected by COVID-19, including over 3870000 deaths worldwide [6]. The pandemic has devastating consequences not only on humans lives but also on the global economy, including more than 8.5 trillion US dollars lost in 2020 and 2021 [7, 8]. Therefore, there is an urgent need to control the pandemic by accelerating the development or production of effective drugs against severe acute respiratory syndrome coronavirus 2 (SARS-CoV-2).
According to the previous studies $[9,10]$, SARS-CoV-2 is the single-stranded enveloped RNA virus with a symmetrical nucleocapsid. The viral genome of SARS-CoV-2 is highly similar to those of SARS-COV and MERS-CoV [11], whose outbreaks happened within two decades in China and Saudi Arabia, respectively. Hence, the drugs or inhibitors designed for SARS-CoV and MERS-CoV were considered to be applied for SARS-CoV-2 as well. For example, SARS-CoV enters into the target cells through the structure spike $(\mathrm{S})$ protein by binding to the angiotensinconverting enzyme 2 (ACE2) receptor [10]. The conservation of spike protein of SARS-CoV-2 suggests that the same interaction between the spike protein and the ACE2 receptor would be remained during the processing of inflection. In addition,

\footnotetext{
Qiaoming Liu is currently a joint PhD student at the Key Laboratory of Tree Genetics and Breeding, Northeast Forestry University. His research interests are machine learning and bioinformatics.

Dr Jun Wan is an assistant professor in the Department of Medical and Molecular Genetics, Indiana University School of Medicine with an adjunct appointment at Department of BioHealth Informatics, School of Informatics and Computing, Indiana University-Purdue University Indianapolis. His current research interests include epigenetics, proteomics and artificial intelligence.

Dr Guohua Wang is a principal investigator at Key Laboratory of Tree Genetics and Breeding, Northeast Forestry University. He received the master's and $\mathrm{PhD}$ degrees in computer science and technology from Harbin Institute of Technology, in 2003 and 2009, respectively. He has been working at the Johns Hopkins University as a postdoctoral fellow from 2014 to 2016. His current research interests include bioinformatics, epigenetics, genomics and machine learning.

Submitted: 30 June 2021; Received (in revised form): 25 August 2021
}

@ The Author(s) 2021. Published by Oxford University Press. All rights reserved. For Permissions, please email: journals.permissions@oup.com 
other small molecules can be potential targets that play critical roles in viral genome replication and gene transcription, e.g. RNA-dependent RNA polymerase (RdRp), or cleavage and activation of the spike protein to enter the host genome and assist genome replication, e.g. type 2 transmembrane serine protease (TMPRSS2). They also keep the similar conservative characteristics among SARS-CoV, MERS-CoV and SARS-CoV-2.

Regardless of their unknown side effects, effective vaccines have been developed against the SARS-CoV-2 infection, like BioNTech vaccine (from Germany), Moderna vaccine (from the USA), Sinopharm vaccine (from China) and AstraZeneca vaccine (from Britain) [12]. Among them, messenger RNA (mRNA)based vaccines are a relatively novel technology that remained to be further proven. Both available mRNA-based vaccines, Moderna and BioNTech, encode the spike protein of SARS-CoV2 binding with the ACE2 receptor. But the SARS-CoV-2 virus has mutated frequently during its evolution and transmission $[13,14]$, resulting in genetic variations in the population of circulating viral strains throughout the COVID-19 pandemic. Until June 2021, multiple major variants of SARS-CoV-2 have dominated the world, e.g. Alpha virus (found in England), Beta virus (found in South Africa), Delta virus (found in India), [15]. Variants of SARS-CoV-2 have different characteristics, leading to unknown efficacy of the existing vaccine against the mutated virus [16]. Hence, design of inhibitors or drugs for specifically mutated SARS-CoV-2 is still necessary and challengeable. Figure 1 presents the timeline of major events related to the SARS-CoV-2 outbreak and vaccine development during 2020 and 2021 until 30 June 2021.

Compared with the traditional drug/inhibitor design process which is time-consuming and costly, computational methods for drug/inhibitor design are highly efficient to predict or identify potential molecules for the disease treatment [17]. Thus, the computer-aided approaches have great potentials for rapidly designing drugs or vaccines for mutated SARS-CoV-2. In the past months, there were several small molecules identified as potential inhibitors targeting SARS-CoV-2, even though more experimental validations are needed on the molecular targets. Among the molecular targets of SARS-CoV-2, main protease $\left(\mathrm{M}^{\text {pro }}\right)$ or 3-chymotrypsin-like protease $\left(3 \mathrm{CL}^{\mathrm{pro}}\right)$ [18], structure proteins (e.g. spike protein), and nonstructure proteases, such as RdRp, and helicase [19], are highly conserved as well as essential to the viral life process. The structural information and functional roles of these major molecular targets against SARS-CoV-2 are summarized in Table S1 in the supplementary material.

We will start the review with diverse computational methods for drug and inhibitor design, followed by detailed descriptions and discussions on the findings of multiple enzymes as valid targets for potential inhibitors to treat coronaviruses diseases.

\section{Insights to the Computer-Aided Drug Design}

Computer-Aided Drug Design (CADD) emerged as an efficient method to uncover potential lead compounds and aiding the development of possible drugs for a wide range of diseases based on the knowledges collected by huge compound libraries [20]. Typically, CADD has three types of approaches, including structure-based drug design (SBDD), ligand-based drug design (LBDD) and virtual screening (VS). Furthermore, machine learning-based drug design (MLDD) has been widely applied with the rapid development of computer science communities [21, 22]. Herrin, we will provide a brief summary of CADD approaches and related databases as seen in Figure 2.

\section{Structure-based drug design}

With the development of chemical biology and structural biology technology, the structural information of more and more drugs has been uncovered, providing essential elements for SBDD. Depending on the 3D structure of targets (proteins), such as Xray crystallography or NMR spectroscopy, SBDD method predicts the potential interaction by evaluating the strength of the binding force between small molecule compounds and targets with the known structure. Molecular docking, a molecular modeling technique as the most basic method in SBDD, allows exhaustive search for the most suitable binding conformation of small molecules in the binding pocket of the protein. The framework of molecular docking is a search algorithm in which the ligand conformation is computed recursively until it converges to the lowest energy. It can effectively determine the ligand molecules that match the spatial and electrical characteristics of the active sites of the target receptors. At present, molecular docking plays an increasingly important role in SBDD [23]. Some common molecular docking software are listed in Table S2, including AutoDock [24], AutoDock Vina [25], AutoDockFR [26], ZDOCK [27], Glide [28], Flare [29], Induced Fit [30], MolDock [31] and M-ZDOCK [32].

\section{Ligand-based drug design}

However, the 3D structures of some drug targets have not been resolved successfully. For such cases, people developed another approach for direct drug design, LBDD, by taking advantage of existing compounds with known biological activities then establishing the relationship between query molecules and the bioactive molecules. In general, LBDD first converts the molecular structure into digital descriptors from a constructed database, e.g. molecular fragments, physiochemical properties, topology and pharmacophores, then generates the relationship between the molecular activities and constructs these descriptors by specific design models. The new drug molecules can be predicted or designed based on proper statistical methods, whereas their possible targets can be inferred from the bioactive molecules having high chemical affinities with the query. In addition to two common LBDD methods, quantitative structure-activity relationship (QSAR) and pharmacophore model [33], other popular LBDD-based software and their corresponding information are listed in Table S3, including McQSAR [34], SYBYL-X [35], TOPS-MODE [36], LigandScout [37], PLIP [38], FindSite-metal [39], CORAL [40].

\section{Virtual screening}

VS is another technique that uses a high-performance computer to analyze large databases of compounds to identify potential drug candidates that bind well to known structural targets [22]. There are two specific strategies for VS: receptor structure-based and ligand similarity-based. Despite different detailed strategies in the VS, the following four steps are essential: (i) preparing target protein and compound database; (ii) docking the molecules in the molecular library with the target one by one; (iii) obtaining a reasonable binding mode according to scores of the binding modes between small molecule and target, then evaluating the binding strength; (iv) purchasing selected preranked screened compounds followed by the activity tests.

The whole VS process can be carried out on computers by indexing the structures of compound molecules in the database instead of purchasing and testing the real compound molecules before the selection. Obviously, VS method is more convenient, 


\begin{tabular}{|c|c|c|c|}
\hline January 4, 2020 & January 30, 2020 & February 11, 2020 & March 11, 2020 \\
\hline $\begin{array}{l}\text { WHO announced } \\
\text { pneumonia cases of } \\
\text { unknown cause. }\end{array}$ & $\begin{array}{l}\text { WHO declared "Public } \\
\text { Health Emergency of } \\
\text { International Concern". }\end{array}$ & $\begin{array}{l}\text { WHO announced name } \\
\text { for new Coronavirus } \\
\text { Disease: COVID-19. }\end{array}$ & $\begin{array}{l}\text { WHO declared novel } \\
\text { coronavirus outbreak } \\
\text { a pandemic. }\end{array}$ \\
\hline March 30, 2020 & April 4, 2020 & April 12, 2020 & May 1, 2020 \\
\hline $\begin{array}{l}\text { FDA authorized use of } \\
\text { Hydroxychloroquine. }\end{array}$ & $\begin{array}{l}\text { WHO reported that } \\
\text { over } 1 \text { million cases of } \\
\text { cOVID-19 had been } \\
\text { confirmed worldwide. }\end{array}$ & $\begin{array}{l}\text { WHO reported that } \\
\text { first } 100,000 \text { deaths } \\
\text { happened. }\end{array}$ & $\begin{array}{l}\text { Remdesivir won } \\
\text { EUA (Emergency } \\
\text { Use Authorization). }\end{array}$ \\
\hline May 21, 2020 & June 4, 2020 & July 14, 2020 & July 21, 2020 \\
\hline $\begin{array}{l}\text { United States and } \\
\text { AstraZeneca formed } \\
\text { vaccine deal. }\end{array}$ & $\begin{array}{l}\text { Lancet, NEJM retracted } \\
\text { COVID-19 studies on } \\
\text { Hydroxychloroquine }\end{array}$ & $\begin{array}{l}\text { Early Moderna Data } \\
\text { Pointed to Vaccine } \\
\text { Candidate's Efficacy. }\end{array}$ & $\begin{array}{l}\text { Vaccines From } \\
\text { AstraZeneca, CanSino } \\
\text { Biologics showed } \\
\text { promising results. }\end{array}$ \\
\hline August 24, 2020 & September 14, 2020 & September 28, 2020 & October 22, 2020 \\
\hline $\begin{array}{l}\text { Remdesivir's clinical } \\
\text { benefited questioned. }\end{array}$ & $\begin{array}{l}\text { Pfizer, BioNTech } \\
\text { expanded phase } 3 \\
\text { trial. }\end{array}$ & $\begin{array}{l}\text { Global COVID-19 deaths } \\
\text { surpassed } 1 \text { million. }\end{array}$ & $\begin{array}{l}\text { FDA approved } \\
\text { Remdesivir as first } \\
\text { COVID-19 drug. }\end{array}$ \\
\hline
\end{tabular}

\begin{tabular}{|c|c|c|c|}
\hline November 16, 2020 & December 14, 2020 & December 30, 2020 & January 12, 2021 \\
\hline $\begin{array}{l}\text { FDA moved rapidly } \\
\text { on EUAs for Pfizer, } \\
\text { Moderna vaccines. }\end{array}$ & $\begin{array}{l}300,000 \text { COVID-19 } \\
\text { Deaths in the United } \\
\text { States. }\end{array}$ & $\begin{array}{l}\text { UK approved emergency } \\
\text { authorization for the } \\
\text { AstraZeneca and Oxford } \\
\text { COVID-19 Vaccine. }\end{array}$ & $\begin{array}{l}\text { WHO convened an } \\
\text { international scientific } \\
\text { consultation on SARS- } \\
\text { CoV-2 variants research. }\end{array}$ \\
\hline February 22, 2021 & February 27, 2021 & March 4, 2021 & April 17, 2021 \\
\hline $\begin{array}{l}\text { The first Delta case } \\
\text { was identified in India. }\end{array}$ & $\begin{array}{l}\text { FDA authorized the } \\
\text { Johnson \& Johnson } \\
\text { COVID-19 vaccine. }\end{array}$ & $\begin{array}{l}\text { Vaccination data were } \\
\text { published on the WHO } \\
\text { Coronavirus Dashboard } \\
\text { for the first time. }\end{array}$ & $\begin{array}{l}\text { COVID-19 deaths } \\
\text { surpassed } 3 \text { million } \\
\text { worldwide. }\end{array}$ \\
\hline
\end{tabular}

\begin{tabular}{|lll} 
May 10, 2021 & June 23, 2021 & June 24, 2021
\end{tabular}

Figure 1. Major events about the SARS-CoV-2 outbreak, transmission, and SARS-CoV-2 vaccine development during 2020 and 2021 until 30 June 2021.

cost efficient and quicker, compared to the experimental synthesis. Table S4 lists some common VS tools with brief introductions, e.g. PyRx [41], LiSiCA [42], MTiOpenScreen [43], iScreen [44], DockThor [45], GOLD [46], FlexX-Scan [47].

\section{Machine learning-based drug design}

Machine learning (ML) is an advanced data analysis method to improve the model automatically through the learning process from data and patterns [48]. ML technologies have been widely used in many fields, such as computer vision [49-51], natural language processing [52-55] and bioinformatics [56-60]. MLDD adopts various algorithms, such as recursive partitioning, support vector machine (SVM), k-nearest neighbors and neural networks [61-63], to investigate the activities of compounds against a target before the clinical trials [64, 65]. For example, Holden et al. [66] applied the SVM classification algorithm to the analysis of structure-activity relationship to predict the inhibition of dihydrofolate reductase by pyrimidines. Meng et al. [67] proposed persistent spectral-based ML models for drug 


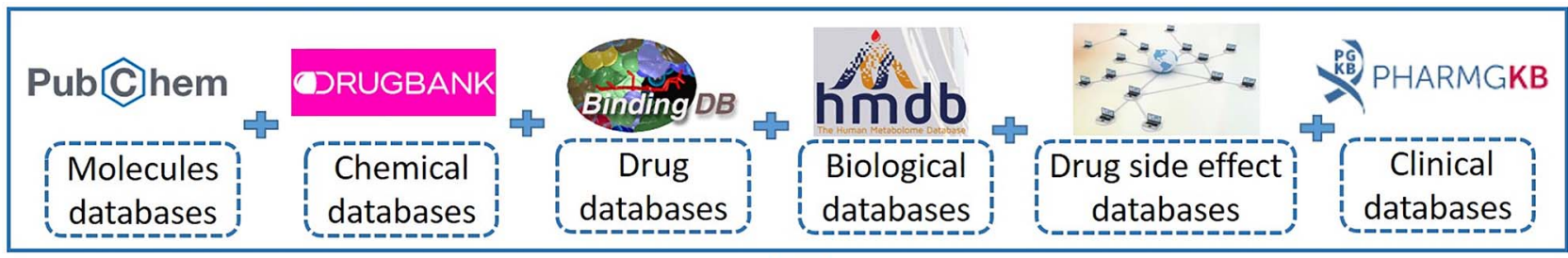

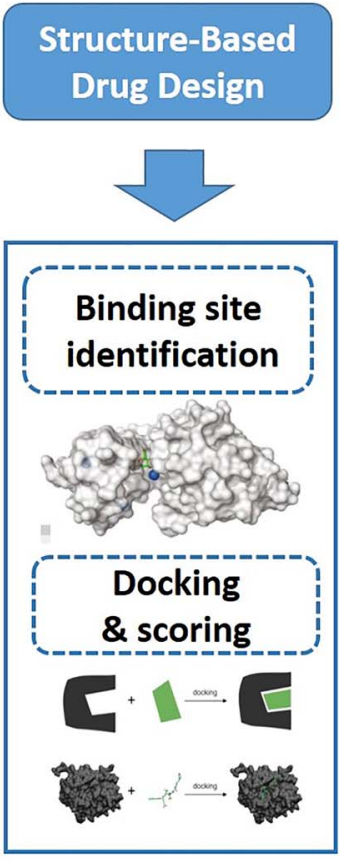

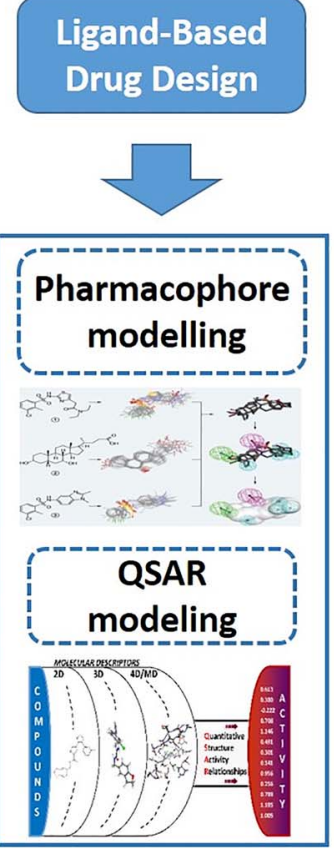

Figure 2. Schematic diagram of Computer-Aid Drug Design approaches (CADD).

design, which consist of the persistent spectral graph, persistent spectral simplicial complex and persistent spectral hypergraph based on the spectral theory. Now the integration of SARS-CoV-2 related studies with modern $\mathrm{ML}$ algorithms becomes a hot topic in drug repurposing models [68-70].

\section{Databases}

Drug discovery and development have initiated many databases containing essential information and knowledge of combinatorial chemistry synthesis, genomics/genetics and drugs or drug candidates. In turn, these databases enhance and improve the CADD. Generally, publicly available datasets about drugs or drug candidates' discovery can be classified into seven scenarios (Table S5): (i) chemical molecules for activities against biological assays (e.g. PubChem [71] and ChEMBL [72]); (ii) chemical features for drug compounds (e.g. DrugBank [73] and SuperDRUG2 [74]); (iii) drugs verified by FDA (e.g. e-Drug3D [75]); (iv) drug targets with genetic and proteomic information (e.g. BindingDB [76] and BioGRID [77]); (v) metabolome or pathway related information (e.g. HMDB [78] and SMPDB [79]); (vi) drug side effects (e.g. DrugMatrix [80] and SIDER [81]); (vii) clinical databases (e.g. AACT database [82] and PharmGKB [83]).

These databases provide a variety of knowledges about drug candidates including physicochemical properties, molecule structure, in addition to diverse data in vitro, in vivo and from clinical. For example, PubChem [71] is a database of chemical

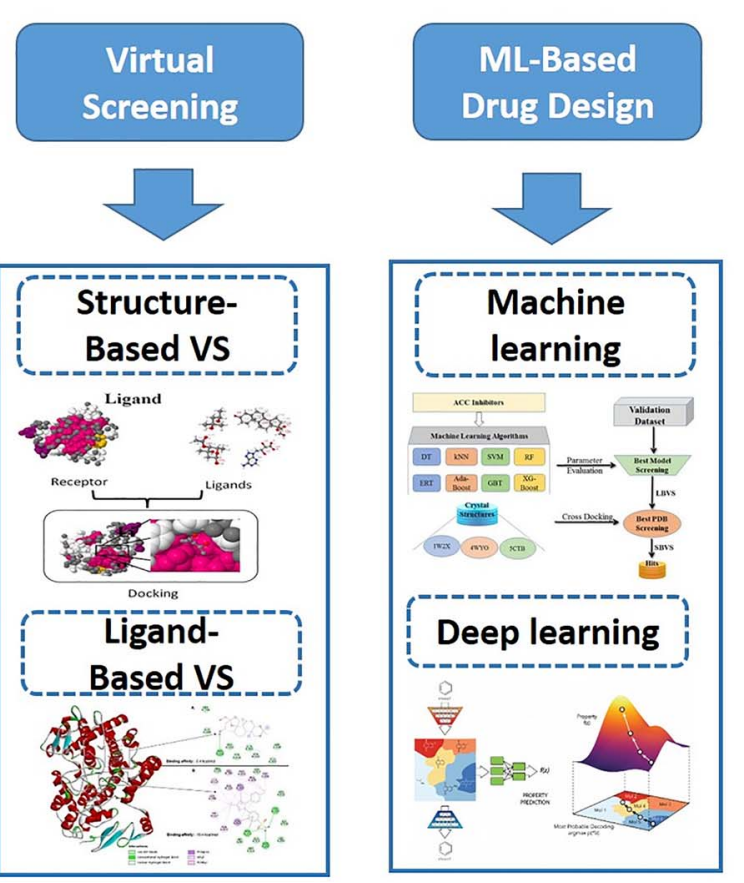

molecules collected by the National Center for Biotechnology Information (NCBI). The NCBI now hosts three dynamically growing primary databases, including 111 million entries of compounds, 293 million entries of substances, and bioactivity results from 1.25 million high-throughput screening assays. Similar to PubChem, ChEMBL [72] is a publicly available database, containing information on binding, functional and ADMET for drug-like bioactive compounds. Currently, the database consists of 5.4 million bioactivity measurements for more than 1 million compounds and 5200 protein targets, which were manually abstracted from the primarily published literatures. There are some databases about drug compounds. For example, DrugBank [73] combines drug data with the information of drug targets and drug actions, which has been widely used in drug-target discovery, drug design, drug docking or screening, and drug interaction prediction. It collects approximately 4900 drug entries including 60\% more FDA-approved small molecules and $10 \%$ more experimental biotech drug rugs. DrugBank has significantly improved the simplicity of its infrastructure and text query searches in the later updates. The e-Drug3D [75] is a 3D chemical structure database for drugs that provides several collections of drugs and commercial drug fragments. It currently contains 1519 annotated 3D structures of 1305 different FDAapproved drugs with molecular weight less than 2000. In the meantime, the drug databases in genetic and proteomic provide another scenario for drug design or discovery. As of September 2018, BioGRID [84] has recorded 1598688 biological 
interactions manually annotated from 55809 publications for 71 species. BioGRID also accumulates details for over 700000 posttranslational modification sites. The recently updated BioGRID also annotates genome-wide CRISPR/Cas9-based screens with gene-phenotype and gene-gene relationships.

During the drug development phases, biological information for therapeutic or metabolism are important and valuable. For example, the HMDB [78], released in 2007, is now considered as the standard metabolomic resource for human metabolic studies including information about human metabolites, physiological concentrations, disease knowledge, chemistry associations, reference spectra and metabolic pathways. Side effects, known as adverse events to a drug, are a crucial research point in drug repurposing. DrugMatrix [80] has been developed based on drug toxicities, consisting of the comprehensive results of thousands of highly controlled and standardized toxicological experiments. It focuses on toxicities research with more than 200 compounds tested in vivo in rat tissues and 125 compounds in the in vitro rat hepatocytes. There is no doubt thought of clinical data which can provide highquality information supporting drug design or discovery. PharmGKB [83] is an open-access database with clinically relevant information, collecting approved drug labels, genedrug interactions and relationships between genotype and phenotype. The corresponding detailed information can be found in Table S5.

\section{CADD against SARS-CoV-2: targeting $\mathrm{M}^{\text {pro }}$}

The main protease $\left(\mathrm{M}^{\text {pro }}\right.$, also known as $3 \mathrm{CL}^{\text {pro }}$ ) is recognized as a key enzyme to play a dominant role in the processing of mediating viral transcription and replication [85]. Since the binding pocket of this enzyme is highly conserved among all coronaviruses, like SARS-CoV, MERS-CoV and HCV, the antiviral drug targeting $\mathrm{M}^{\text {pro }}$ may be effective against SARS-CoV-2 as well [86]. Indeed, a lot of recent studies have been published that employed CADD to discover anti-SARS-CoV-2 agents against $\mathrm{M}^{\text {pro }}$ by different strategies, e.g. structure-based, ligand-based, VS or ML-based approaches (Figure 3).

For example, people used the structure-based docking approaches to predict the inhibitory activity and help drug design against SARS-CoV-2 $\mathrm{M}^{\text {pro }}$ [87]. Yu et al. [88] screened potential drugs by molecular docking to examine the effects of some common antiviral drugs like ribavirin, remdesivir, chloroquine and honeysuckle (a traditional Chinese medicine) as shown in Figure 4. Importantly, they recognized the luteolin as the control molecule is the main flavonoid in honeysuckle (Figure 3), which had a high binding affinity to the same sites of the main protease of SARS-CoV-2. Motonori Tsuji [4] performed structural refinement and energy calculations in the presence of peptidomimetic $\alpha$-ketoamide inhibitors (PDB ID: 6Y2G, shown in Figure $5 \mathrm{~A}$ ). They found 28 bioactive compounds, including CHEMBL3236740, CHEMBL1447944 and others, were identified as effective anti-SARS-CoV-2 drug candidates (Figure 3). Singh et al. [89] identified several compounds, glucogallin, mangiferin, N3, remdesivir and $\mathrm{X} 77$ which had stronger binding affinities with $\mathrm{M}^{\mathrm{p} r o}$. Furthermore, the results suggest that the phlorizin had the lowest binding free energy toward $\mathrm{M}^{\text {pro }}$ (Figure 4), followed by glucogallin and mangiferin.

However, long-range interactions have not been discussed as often as the short-range interactions during the selection of candidate inhibitors. Sencanski et al. [90] used the protocol with both long-range and short-range interactions to select inhibitor candidates. They applied the informational spectrum method and molecular docking for small molecules to search the DrugBank database. Interestingly, 57 drugs were identified as potential SARS-CoV-2 $\mathrm{M}^{\text {pro }}$ inhibitors. Additionally, tinospora crispa (Figure 3) was recognized as one potential COVID-19 Mpro inhibitor based on another independent molecular docking study [91].

To rapidly discover lead compounds for clinical treatments, Jin et al. [86] investigated a mechanism-based inhibitor (N3) by CADD and the crystal structure of $\mathrm{M}^{\text {pro }}$ of SARS-CoV-2 with complex N3. They built a predicted model by integrating structurebased virtual and high-throughput screening, which assayed over 10000 compounds as inhibitor candidates of $\mathrm{M}^{\text {pro }}$. One of these compounds, named ebselen, also had potential antiviral ability in cell-based assays (Figures 3 and 4).

Besides small molecules, some researchers have tried much effort to find potential candidates from natural products (NPs) against SARS-CoV-2 [92] [93]. For example, Ibrahim et al. [94] screened the MolPort database with molecular docking techniques. The top 5000 natural-like products (NLPs) were chosen according to the corresponding docking scores, like MolPort-000708-794 and MolPort-044-179-844 (Figure 3). They found that the most promising NPs shared the same binding mode with key amino acid residues including HIS164, HIS163 and GLU166 based on molecular docking and molecular dynamics. The findings of these studies are expected to provide insight into the field of COVID-19 drug discovery [95-102].

Some recent studies have shown the feasibility of employing VS in inhibitor design of targeting $\mathrm{M}^{\text {pro }}$. For example, Abel et al. [103] developed a VS method with both ligand- and structurebased approaches. The proposed VS was performed for two NPs databases, Super Natural II [104] and Traditional Chinese Medicine [105]. Additionally, they used an integrated drug repurposing approach to identify potential inhibitors against SARSCoV-2 $\mathrm{M}^{\text {pro }}$. Some drugs, like naldemedine, SN00017653, and pseudostellarin C, were identified as potential inhibitors for the first time (Figure 3). Lee et al. [1] identified potential inhibitors against COVID-19 from the Korea Chemical Bank drug repurposing (KCB-DR) database [106]. The results suggest ceftaroline fosamil (Figure 4) and the hepatitis C virus (HCV) protease inhibitor telaprevir as potential inhibitors against $\mathrm{M}^{\text {pro }}$.

Although some drugs, such as remdesivir, favipiravir or dexamethasone, have been known beneficial for COVID-19 treatment, they have limitations clinically for different reasons. Hence, Nayak et al. [107] accomplished the VS of a variety of US-FDA-approved drugs using computer-aided tools. The USFDA-approved drug structures were selected from DrugBank. Among them, arbutin, terbutaline, barnidipine, tipiracil and aprepitant were identified as potential hits. Moreover, tipiracil and aprepitant bound to the $\mathrm{M}^{\text {pro }}$ consistently, demonstrating potentially promising effects in pharmacologic treatments for COVID-19.

Structure-based VS is adopted to predict the best interaction between a ligand and a molecular target by scoring function. For example, Kumar et al. [108] utilized structure-based VS to identify hit molecules binding with the highest affinity to $\mathrm{M}^{\text {pro }}$. The results indicated that the hydrogen bonding and hydrophobic interactions are the major contributing factors in binding pocket of COVID-19 $\mathrm{M}^{\text {pro }}$. In addition, Hage-Melim et al. [109] used VS approaches based on the structure of the enzyme and two compound libraries to identify apixaban as a potential drug for future treatment of COVID-19. Fischer et al. [110] used shape screening and two docking protocols relevant for pharmacokinetics to narrow down commercially available compounds, leading to the natural compounds (-)-taxifolin and rhamnetin as 


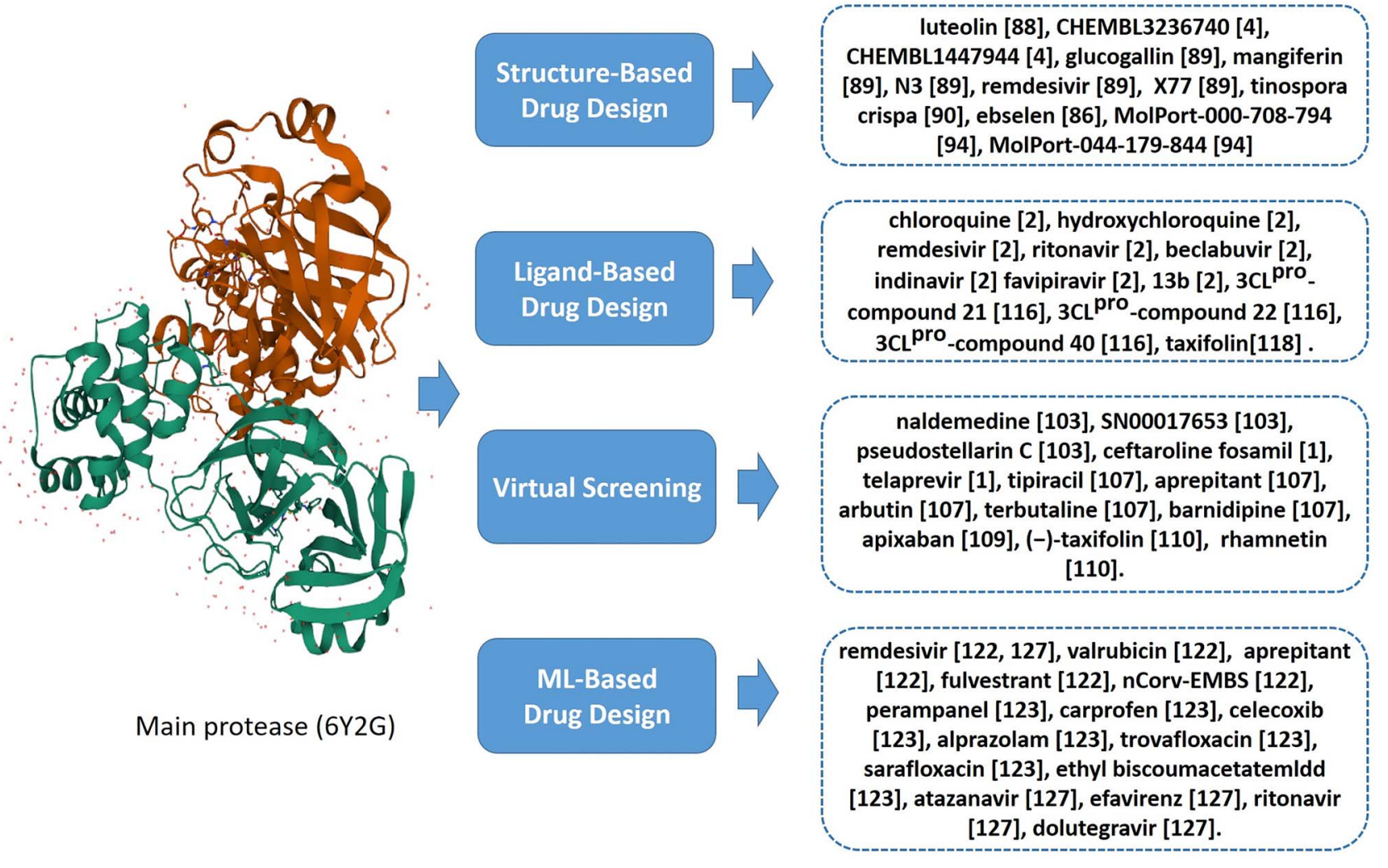

Figure 3. Summary of literatures using CADD to target $\mathrm{M}^{\text {pro }}$ of SARS-CoV-2.

potential inhibitors of $\mathrm{M}^{\text {pro }}$ (Figure 3). These new findings may bring insight into our further understanding and discovery of inhibitor candidates targeting $\mathrm{M}^{\mathrm{pro}}[5,111-113]$.

The reliability and accuracy of the ligand-based CADD method have been proven [114]. Han et al. [2] utilized the ligand-protein docking and molecular dynamic simulation for $a b$ initio study to explore the binding mechanism or inhibitory ability by comparing two types of drugs: (i) clinically approved drugs including chloroquine, hydroxychloroquine, remdesivir, ritonavir, beclabuvir, indinavir and favipiravir, and (ii) a designed $\alpha$-ketoamide inhibitor (13b) (Figure 3). The results suggested chloroquine had the strongest binding affinity with $\mathrm{M}^{\text {pro }} / 3 \mathrm{CL}^{\text {pro }}$. Meanwhile, inhibitor $13 \mathrm{~b}$ has a higher research priority to treat the SARS-CoV-2 since its improved inhibition efficiency. Eleftheriou et al. [115] uncovered that anticoagulant therapy has been proposed for the treatment of severe SARS-CoV-2 caused pneumonia, particularly, DPP-4 inhibitors may be more effective for SARS-CoV-2-infected diabetic patients.

QSAR model, the classical ligand-based CADD method, was also utilized in recent inhibitor design studies. For example, Ishola et al. [116] selected SARS coronavirus 3C-like protease $\left(3 \mathrm{CL}^{\text {pro }}\right)$ inhibitors data from the CHEMBL database. They constructed a QSAR model using the data with high correlations, which made the model statistically significant. The analysis revealed that $3 \mathrm{CL}^{\text {pro }}$-compound $21,3 \mathrm{CL}^{\text {pro }}$-compound 22, 3CL pro compound 40 complexes (Figure 3) were steadier than the baseline complex (3CL pro $-X 77)$. Alves et al. [3] developed QSAR models of these inhibitors then applied these models in VS with drugs in the DrugBank by conducting similarity searching and molecular docking in parallel. As a result, 42 compounds were identified as consensus computational hits. They were reported coincidentally in subsequent experimental screening studies (https://o pendata.ncats.nih.gov/covid19/). Kumar et al. [117] developed a 2D-QSAR model based on multiple linear regression (MLR) with $3 \mathrm{CL}^{\text {pro }}$ inhibitors. The proposed model clearly exhibited the structural features which enhanced the inhibitory activity against the $3 \mathrm{CL}^{\text {pro }}$ enzyme. Additionally, the most and least active molecules were investigated using molecular docking tools to explore the molecular interactions involved in binding. Gogoi et al. [118] screened a library of 44 citrus flavonoids using molecular docking. The nontoxic compounds were further investigated with molecular dynamics simulation and predicted activity (IC50 value) with the 3D-QSAR model. They suggested taxifolin (Figure 3) as a potential inhibitor against SARS-CoV-2 $\mathrm{M}^{\text {pro }}$ which can be further analyzed by subsequent experiments for treatment of COVID -19. There are more literatures about ligand-based CADD in inhibitor candidates designing targeting $\mathrm{M}^{\text {pro }}[119,120]$.

As ML techniques can be applied to the predictive scenario based on previous knowledges and well-known patterns, some recent studies have contributed to the development of MLbased CADD methods targeting $\mathrm{M}^{\text {pro }}$. For example, Huang et al. [121] developed a biological activity-based modeling (BABM) approach, by which the compound activity can be predicted for a new target or other assays by using profiles across multiple well-defined assays. This model obtained 311 compounds against SARS-CoV-2, 32\% of which showed antiviral activity in a cell culture live virus assay. More importantly, the most potent compounds presented nanomolar concentration levels for a half-maximal inhibitory. Nayarisseri et al. [122] proposed a shape-based ML method, which generates the 3D shaped pharmacophoric features of the seed compound. Furthermore, molecular docking was performed with optimized potential for liquid simulations (OPLS) algorithms to recognize high affinity 


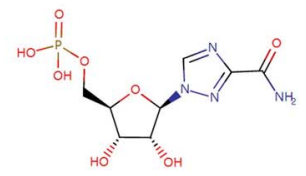

Ribavirin: $-5.8 \mathrm{kcal} / \mathrm{mol}$ [88]

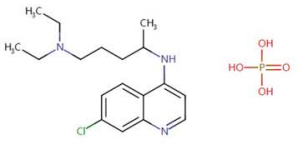

Chloroquine: $-16.1 \mathrm{kcal} / \mathrm{mol}[2]$

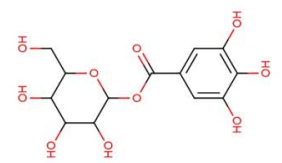<smiles>C[C@@H]1[C@@H](CO)O[C@@H](Oc2cc(O)cc(O)c2C(=O)CCc2ccc(O)cc2)[C@H](O)[C@H]1O</smiles>

Phlorizin: $-7.0 \mathrm{kcal} / \mathrm{mol}$ [89]

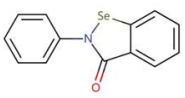

Ebselen, not provided [86]
Glucogallin: $-7.0 \mathrm{kcal} / \mathrm{mol}$ [89]

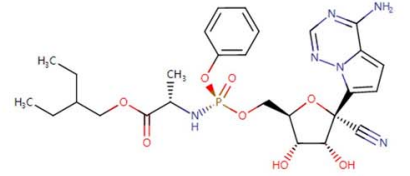

Remdesivir: $-7.2 \mathrm{kcal} / \mathrm{mol}$ [89]<smiles>O=c1cc(-c2ccc(O)c(O)c2)oc2cc(O)cc(O)c12</smiles>

Luteolin: -5.5 kcal/mol [88]<smiles>O=c1c2cc(O)c(O)cc2oc2cc(O)c(C3OC(CO)C(O)C(O)C3O)c(O)c12</smiles>

Mangiferin: $-8.5 \mathrm{kcal} / \mathrm{mol}$ [89]<smiles>CN=C(NC)NCCC[C@H](N)C(=O)O</smiles>

N3: -7.9 kcal/mol [86] ${ }_{\mathrm{CH}_{2}}$

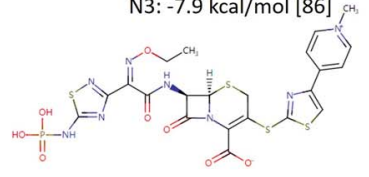

Ceftaroline fosamil: $-47.5 \mathrm{kcal} / \mathrm{mol}$ [1]
Figure 4. Two-dimensional (2D) chemical structures of some drugs and drug candidates with corresponding available binding energies to $\mathrm{M}^{\text {pro }}$. All structures were collected from the DrugBank database.

compounds targeting $\mathrm{M}^{\text {pro }}$. The shape-based ML reported that remdesivir, valrubicin, aprepitant and fulvestrant were the best therapeutic drugs (Figure 3) since the highest affinities with the target protein. They also found a novel compound 'nCorv-EMBS', which is not included in public chemical databases (PubChem, ZINC or ChEMBL) so far. The results of toxicity analysis suggested nCorv-EMBS was valuable to further research as the main protease inhibitor in COVID-19 [122].

Inspired by ensemble learning, Gimeno et al. [123] first applied molecule docking against the structure of $\mathrm{M}^{\text {pro }}$ using three popular tools: Glide [28], FRED [124] and AutoDock Vina [25]. Then, they proposed a hybrid ensemble approach to generate hypothetic binding modes replying on three score functions. Seven possible SARS-CoV-2 $\mathrm{M}^{\text {pro }}$ inhibitors were predicted including perampanel, carprofen, celecoxib, alprazolam, trovafloxacin, sarafloxacin and ethyl biscoumacetate (Figure 3). Battisti et al. [125] also proposed an inhibitor predicting framework, which not only combines molecular dynamics simulations with molecular docking but also focuses on the feature information of pharmacophore modeling and the flexibility of molecular dynamics simulations simultaneously. The proposed approach identified 10 compounds with high coronavirus inhibition potential.

In addition to the traditional data-driven ML modeling, some studies used deep learning-based approaches to predict potential inhibitors of SARS-CoV-2 Mpro [126]. For example, Park et al. [127] recognize some potentially drugs against (a)

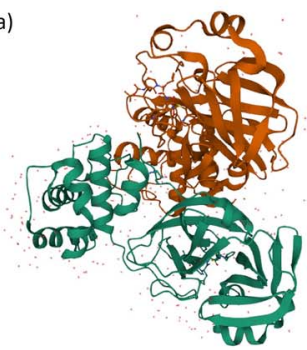

Main protease $(6 \mathrm{Y} 2 \mathrm{G})$

(c)

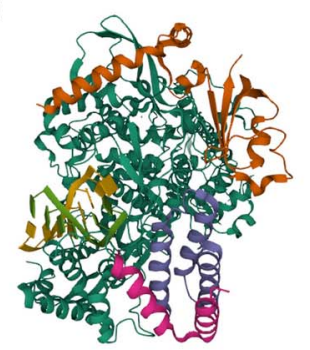

SARS-CoV-2 RdRp/RNA complex (6XQB)

(e)

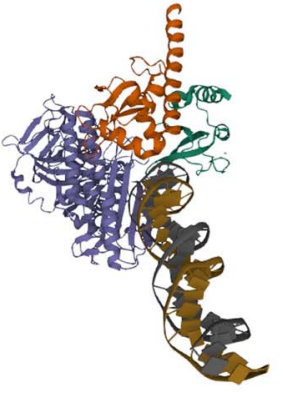

Human PARP-1 (4DQY)

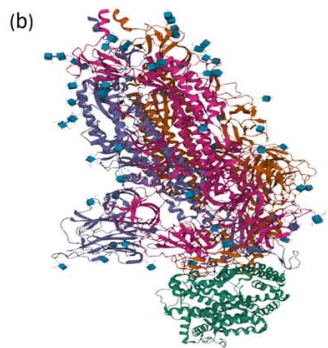

SARS-CoV-2 S-ACE2 complex (7DF4)

(d)

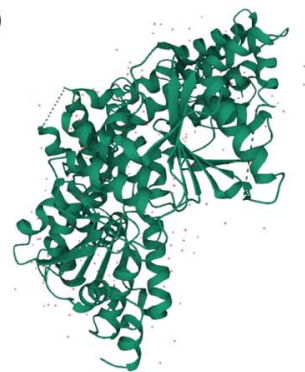

SARS-CoV-2 Helicase complex (1PJR)

(f)

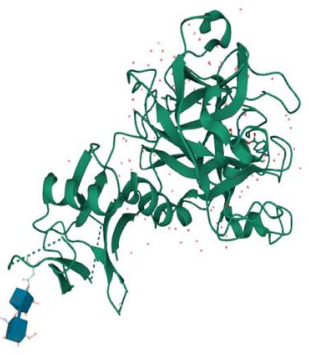

TMPRSS2 protein (7MEQ)
Figure 5. Crystal structures (orthorhombic form) of target proteins and formed complexes. (A) SARS-CoV-2 (2019-nCoV) main protease and potential inhibitors. (B) SARS-CoV-2 S-ACE2 complex. (C) SARS-CoV-2 RdRp/RNA complex. (D) SARSCoV-2 Helicase complex. (E) Human PARP-1 bound to a DNA double-strand break. (F) Human TMPRSS2 with Nafamostat. All structures were collected from the protein data bank database.

SARS-CoV-2 using the pretrained deep learning drug-target interaction model called Molecule Transformer-Drug Target Interaction. They found that atazanavir, remdesivir, efavirenz, ritonavir and dolutegravir were the chemical compounds, showing an inhibitory potency against the SARS-CoV-2 3CL pro. Interestingly, they found that lopinavir, ritonavir and darunavir, which were designed to target viral proteinases, also bound to the replication complex components of SARS-CoV-2. Bung et al. [128] employed deep generative and predictive models to discover small molecules targeting inhibiting $\mathrm{M}^{\text {pro }}$. The transfer learning and reinforcement learning was applied to optimize the proposed deep learning model, which learned chemical space around the protease inhibitors. Other features, including multiple physicochemical property filters and VS scores, were used for the final screening as well. Finally, they proposed 33 potential compounds for further synthesis and testing against SARS-CoV-2. Based on the structural model, Zhang et al. [129] performed a deep learning-based VS method to rank and identify 
protein-ligand interactions. The summary of drugs or inhibitors targeting SARS-CoV-2 $\mathrm{M}^{\text {pro }} / 3 \mathrm{CL}^{\text {pro }}$ can be found in Table S6.

\section{CADD against SARS-CoV-2: targeting the structure protein}

SARS-CoV-2 contains four structural proteins, including membrane protein $(\mathrm{M})$, spike protein $(\mathrm{S})$, envelope protein $(\mathrm{E})$ and nucleocapsid protein $(\mathrm{N})$, in addition to 16 nonstructural proteins (NSP1-16 as seen in the next section) [130]. Among them, the $\mathrm{S}$ protein can mediate the process of coronaviruses entering into host cells, so it becomes an attractive antiviral target for COVID-19 treatment.

Computational approaches have been developed to predict potential SARS-CoV-2 inhibitors targeting S protein. Previous studies demonstrated ACE2 as the key factor for SARS-CoV2 to enter the host cells being bound by the spike protein of SARS-CoV-2 (Figure 5B). Hence, ACE2 becomes another common target of drug intervention. Wen et al. [131] investigated the existing drugs according to their abilities to block the binding of $\mathrm{S}$ protein to ACE2. According to the pathogenesis of SARSCoV-2 from the perspective of S protein and ACE2 binding, they found some substances, including peptide P6, griffithsin, EK1 and extracts from traditional chinese medicine, which fought against SARS-CoV-2 through binding ACE2 receptor, S protein, or inhibiting the host and virus. Faria et al. [132] also focused on the molecules that can inhibit the interaction between the $\mathrm{S}$ protein and human ACE2. They discovered some molecules at the interaction sites: four molecules in Tyr-491(Spike)-Glu37(ACE2) and one in Gly-488(Spike)-Lys-353(ACE2). Furthermore, they found that the molecule 1629 and the molecule 2542 had significant inhibitory effects on the site of Gly488-Ly353 and Tyr491-Glu37, respectively, suggesting further laboratory tests on the combination of these molecules that can work at two interaction sites simultaneously. Additionally, the human furin protease, cleaving the S1-S2 domains involved in entering the host cell, may become the third target. CUBUK et al. [133] docked five drug molecules, favipiravir, hydroxychloroquine, remdesivir, lopinavir and ritonavir, on not only S protein and main protease but also human furin protease. The results of molecular docking revealed that the human furin protease can be a potential target of SARS-CoV-2, whereas remdesivir, a nucleic acid derivative, can be used as a template for designing novel furin protease inhibitors to fight against the disease. Taking advantage of the DrugBank and PubChem, Unni et al. [134] identified Bisoxatin (DB09219), a laxative drug, as a promising repurposable drug to develop a new chemical compound for inhibiting SARS-CoV-2 entry into the host, even though Bisoxatin was used to treat constipation and preparation. GR 127935 hydrochloride hydrate, GNF-5, RS504393, and eptifibatide acetate were found to connect to viral binding motifs of ACE2 receptor by Tomar et al. [135]. Table S6 presents the summary of drugs or inhibitors targeting SARS-CoV-2 S protein and ACE2.

Many computational approaches also focused on potential SARS-CoV-2 inhibitors targeting $\mathrm{M}$ protein, $\mathrm{N}$ protein and $\mathrm{E}$ protein, which were believed to be useful for further structure-based VS and other CADD drug and vaccine design. Dong et al. [136] searched the homologous templates of all structural proteins of SARS-CoV-2, including S, E and N proteins. Banerjee et al. [137] recognized micromolecules of inhibitors targeting $M$ protein and E proteins of SARS-CoV-2 by integrating docking and simulation methods. They investigated some compounds from an Indian medicinal plant source (Azadirachta indica or Neem) and found 70 compounds against these two proteins. With molecular dynamics simulations, a few common compounds binding to both $\mathrm{M}$ and $\mathrm{E}$ proteins were recognized as potentially inhibit their functions. Table $\mathrm{S} 6$ lists drugs or inhibitors targeting SARS-CoV-2 proteins with essential information.

\section{CADD against SARS-CoV-2: Targeting the nonstructure protein}

SARS-CoV-2 nonstructure proteins can be potential targets to inhibit SARS-CoV-2 as well. For example, RdRp, as shown in Figure 5C, plays a crucial role in the viral cycle of coronaviruses, particularly the replication of the viral genome, with the assistance of nonstructure proteins, NSP7 and NSP8, in a polymerase complex. It is not surprising to see that RdRp has been recognized as an important coronavirus target for drug design. Since SARS-CoV-2 has high similarity with other SARS viruses, targetbased VS and molecular docking on antiviral molecules of the SARS explored that the antiviral galidesivir had promise against SARS-CoV-2 as well [138]. Quinupristin was identified as one candidate which can bind in the RNA tunnel of RdRP and block the path and access on both sides with potentials to prevent viral replication and RNA synthesis [139]. Wu et al. [140] systematically compared SARS-CoV-2 genes encoding proteins with that from other coronaviruses, then predicted and built 19 structures with homology modeling. Based on ZINC drug database and their own NPs database, they found 78 antiviral drugs for SARS-CoV-2, which are currently on the market or undergoing clinical trials.

Helicase is another macromolecule viral replication enzyme, responsible for separating DNA and RNA into two singlestranded nucleic acids in the coronaviruses viral cycle unwinding (Figure 5D). Some studies have also suggested drugs and NPs as potential SARS-CoV-2 helicase inhibitors. For example, one study suggests that vapreotide and atazanavir, two approved drugs for treating AIDS-related diarrhea and HIV infection, are observed to interrupt the activities of the SARS-CoV-2 helicase significantly [141]. Mirza et al. [142] have proposed an integrative VS and molecular dynamics simulations approach for targeting the main protease, RdRp and helicase, which warrants in vitro testing to evaluate compound efficacy.

Iftikhar et al. [143] focused on a small molecule that specifically binds to three essential proteins ( $\mathrm{RdRp}, 3 \mathrm{CL}^{\text {pro }}$ and helicase). They found three FDA-approved drugs binding to $3 \mathrm{CL}^{\text {pro }}$, one drug-like molecule binding to RdRp, and two drug-like molecules specifically interacting with helicase.

The poly-ADP-ribose polymerase 1 (PARP1, shown in Figure 5E) is also critical for viral replication [144-146]. Ge et al. [147] developed a data-driven drug repositioning framework combining ML and statistical analysis approaches to explore potential drug candidates against SARS-CoV-2, by integrating their large-scale data including knowledge graphs and transcriptome data from public domain and literatures. Based on the model, CVL218, a PARP1 inhibitor, was recognized as the repurposed therapeutic agent for COVID-19.

The host serine protease TMPRSS2 has a pivotal role in the viral entry of SARS-CoV-2 (Figure 5F). In the study conducted by Singh et al. [89], they uncovered the strong binding affinity between TMPRSS2 and compounds, glucogallin, mangiferin, N3, remdesivir and X77. Among them, mangiferin showed the lowest binding free energy, followed by phlorizin and glucogallin.

Additionally, more studies focused on other nonstructure proteases in the viral replication/transcription process, such as NSP15 protein [148] (belongs to the EndoU enzyme family), C3 
(complement component 3) [149] and N7-MTase [150] (GuanineN7 Methyltransferase). According to the findings, glisoxepide, and idarubicin, used to treat diabetes and leukemia, respectively, were identified as the stronger binder of EndoU enzyme [151]. We summarized drugs or inhibitors targeting SARS-CoV-2 macromolecules as seen in Table S6.

\section{Conclusion}

Since the outbreak of COVID-19, people around the world have put much effort into investing vaccines and drugs against SARSCoV-2. CADD and ML techniques have been employed in many studies to target SARS-CoV-2 macromolecules, which are considered as feasible options to speed up the processes for drug design and discovery. Our paper reviewed the theory and applications of these approaches with specific databases from these studies. We explored the new findings of inhibitors as potential interventions and treatments of COVID-19.

However, considering the variations of SARS-CoV-2, we are still facing big challenges to make sure that developed vaccines and drugs can keep efficient for different viral strains with specific mutations. It is known that structural variations on or even close to the binding sites could dramatically impact ligand binding properties. Gossen et al. [152] redefined the druggability of the proteins as an integrated chemical space generated by multiple conformations of binding sites when ligand binding. This process revealed the unique blueprint of SARS-CoV-2 $\mathrm{M}^{\text {pro }}$, leading to a definition of a pharmacophore based on the specific structure, which provides a strong foundation for rational drug design for SARS-CoV-2 Mpro. Ugurel et al. [153] analyzed 3458 SARS-CoV-2 genome sequences isolated from 58 countries. They found the incidence of C17747T and A17858G mutations on helicase (NSP13) were significantly higher than others. However, four drugs, including cangrelor, fludarabine, folic acid and polydatin, interrupted both the wild type and mutant SARS-CoV2 helicase, suggesting that they can be the most potent drugs. We expect that our review can bring insight to identify antiviral inhibitors and potential drug candidates against diverse SARSCOV-2 variants.

\section{Key Points}

- Discovering potential inhibitors or drugs of SARS-CoV2 is critical in mitigating the pandemic impact of COVID-19.

- We give a brief overview of existing computer-aid drug design methods and biological databases used in predicting drugs or inhibitors.

- We provide a systematic review of current knowledge, latest findings using computational methods to discover protein inhibitors of SARS-CoV-2.

\section{Supplementary data}

Supplementary data are available online at https://academi c.oup.com/bib.

\section{Funding}

This work has been partially supported by the National Natural Science Foundation of China (62072095, 61771165), the National Key R\&D Program of China (2021YFC2100100), the Innovation Project of State Key Laboratory of Tree Genetics and Breeding (Northeast Forestry University) (2019A04) to Dr. Guohua Wang.

\section{References}

1. Kumar R, Kumar V, Lee KW. A computational drug repurposing approach in identifying the cephalosporin antibiotic and anti-hepatitis C drug derivatives for COVID-19 treatment. Comput Biol Med 2021;130:104186.

2. Han Y, Wang Z, Ren J, et al. Potential inhibitors for the novel coronavirus (SARS-CoV-2). Brief Bioinform 2021;22(2):1225-31.

3. Alves VM, Bobrowski T, Melo-Filho CC, et al. QSAR Modeling of SARS-CoV M(pro) inhibitors identifies sufugolix, cenicriviroc, proglumetacin, and other drugs as candidates for repurposing against SARS-CoV-2. Mol Inform 2021;40(1):e2000113.

4. Tsuji M. Potential anti-SARS-CoV-2 drug candidates identified through virtual screening of the ChEMBL database for compounds that target the main coronavirus protease. FEBS Open Bio 2020;10(6):995-1004.

5. Singh S, Florez H. Bioinformatic study to discover natural molecules with activity against COVID-19. F1000Res 2020;9:1203.

6. Senger MR, Evangelista TCS, Dantas RF, et al. COVID-19: molecular targets, drug repurposing and new avenues for drug discovery. Mem Inst Oswaldo Cruz 2020;115:e200254.

7. Tisdell CA. Economic, social and political issues raised by the COVID-19 pandemic. Economic analysis and policy 2020;68:17-28.

8. He H, Harris L. The impact of Covid-19 pandemic on corporate social responsibility and marketing philosophy. $J$ Bus Res 2020;116:176-82.

9. Vivekanandhan $K$, Shanmugam $\mathrm{P}$, Barabadi $\mathrm{H}$, et al. Emerging therapeutic approaches to combat COVID-19: present status and future perspectives. Front Mol Biosci 2021;8:604447.

10. Lu J, Liu X. Structural biology aids the research of new antiCOVID-19 drugs. Current Organic Synthesis 2020;17(3):162-3.

11. Vougogiannopoulou K, Corona A, Tramontano E, et al. Natural and nature-derived products targeting human coronaviruses. Molecules 2021;26(2):448.

12. Forni G, Mantovani A. COVID-19 vaccines: where we stand and challenges ahead. Cell Death Differ 2021;28(2):626-39.

13. Fang S, Liu S, Shen J, et al. Updated SARSCoV-2 single nucleotide variants and mortality association. J Med Virol 2021;jmv.27191. https://doi.o rg/10.1101/2021.01.29.21250757.

14. Liu S, Shen J, Fang S, et al. Genetic spectrum and distinct evolution patterns of SARS-CoV-2. Front Microbiol 2020;11:593548.

15. Starr TN, Greaney AJ, Addetia A, et al. Prospective mapping of viral mutations that escape antibodies used to treat COVID-19. Science 2021;371(6531):850-4.

16. Yadav PD, Sapkal GN, Abraham P, et al. Neutralization of variant under investigation B.1.617 with sera of BBV152 vaccinees. bioRxiv 2021April 23, 2021. https://doi.org/10.1101/2021.04.23.441101 preprint: not peer reviewed.

17. Mishra AK, Tewari SP. In silico screening of some naturally occurring bioactive compounds predicts potential inhibitors against SARS-COV-2 (COVID-19) protease. arXiv preprint arXiv:2004.01634 2020. 
18. Illian DN, Siregar ES, Sumaiyah S, et al. Potential compounds from several Indonesian plants to prevent SARS-CoV-2 infection: a mini-review of SARS-CoV-2 therapeutic targets. Heliyon 2021;7(1):e06001.

19. Lima WG, Brito JCM, Overhage J, et al. The potential of drug repositioning as a short-term strategy for the control and treatment of COVID-19 (SARS-CoV-2): a systematic review. Arch Virol 2020;165(8):1729-37.

20. Keum YS, Jeong YJ. Development of chemical inhibitors of the SARS coronavirus: viral helicase as a potential target. Biochem Pharmacol 2012;84(10):1351-8.

21. Wang Z, Sun H, Yao X, et al. Comprehensive evaluation of ten docking programs on a diverse set of proteinligand complexes: the prediction accuracy of sampling power and scoring power. Phys Chem Chem Phys 2016;18(18): 12964-75.

22. Zhao L, Ciallella HL, Aleksunes LM, et al. Advancing computer-aided drug discovery (CADD) by big data and data-driven machine learning modeling. Drug Discou Today 2020;25(9):1624-38.

23. Adasme MF, Parisi D, Sveshnikova A, et al. Structure-based drug repositioning: potential and limits. Semin Cancer Biol 2021;68:192-8.

24. Goodsell DS, Morris GM, Olson AJ. Automated docking of flexible ligands: applications of AutoDock. J Mol Recognit 1996;9(1):1-5.

25. Trott O, Olson AJ. AutoDock Vina: improving the speed and accuracy of docking with a new scoring function, efficient optimization, and multithreading. J Comput Chem 2010;31(2):455-61.

26. Ravindranath PA, Forli S, Goodsell DS, et al. AutoDockFR: advances in protein-ligand docking with explicitly specified binding site flexibility. PLoS Comput Biol 2015;11(12):e1004586.

27. Chen $\mathrm{R}$, Li L, Weng Z. ZDOCK: an initial-stage proteindocking algorithm. Proteins 2003;52(1):80-7.

28. Friesner RA, Banks JL, Murphy RB, et al. Glide: a new approach for rapid, accurate docking and scoring. 1. Method and assessment of docking accuracy. J Med Chem 2004;47(7): 1739-49.

29. Paranjpe RS, Cusenza A. FLARE: An integrated software package for friction and lubrication analysis of automotive engines-Part II: Experimental validation. In: SAE Technical Paper, 1992. https://doi.org/10.4271/920488.

30. Bosshard HR. Molecular recognition by induced fit: how fit is the concept? Phys Ther 2001;16(4):171-3.

31. Thomsen R, Christensen MH. MolDock: a new technique for high-accuracy molecular docking. J Med Chem 2006;49(11):3315-21.

32. Pierce $\mathrm{B}$, Tong $\mathrm{W}$, Weng Z. M-ZDOCK: a grid-based approach for $\mathrm{C} n$ symmetric multimer docking. Bioinformatics 2005;21(8):1472-8.

33. Yang $\mathrm{SQ}$ Ye $\mathrm{Q}$ Ding JJ, et al. Current advances in ligand-based target prediction. WIREs Comput Molecular Sci 2020;11(3):e1504.

34. Vainio MJ, Johnson MS. McQSAR: a multiconformational quantitative structure - activity relationship engine driven by genetic algorithms. J Chem Inf Model 2005;45(6):1953-61.

35. Sybyl X. Molecular modeling software packages (Version 2.0). TRIPOS Associates, 2012.

36. González MP, Helguera AM, Díaz HG. A TOPS-MODE approach to predict permeability coefficients. Polymer 2004;45(6):2073-9.
37. Wolber G, Langer T. LigandScout: 3-D pharmacophores derived from protein-bound ligands and their use as virtual screening filters. J Chem Inf Model 2005;45(1):160-9.

38. Salentin S, Schreiber S, Haupt VJ, et al. PLIP: fully automated protein-ligand interaction profiler. Nucleic Acids Res 2015;43(W1):W443-7.

39. Brylinski M, Skolnick J. FINDSITE-metal: integrating evolutionary information and machine learning for structurebased metal-binding site prediction at the proteome level. Proteins 2011;79(3):735-51.

40. Toropova AP, Toropov AA. CORAL software: prediction of carcinogenicity of drugs by means of the Monte Carlo method. Eur J Pharm Sci 2014;52:21-5.

41. Dallakyan, S. and A.J. Olson, Small-molecule library screening by docking with PyRx, in Chemical Biology. 2015, Springer. p. 243-50 1263 New York, NY Methods in Molecular Biology.

42. Lešnik S, Štular T, Brus B, et al. LiSiCA: a software for ligand-based virtual screening and its application for the discovery of butyrylcholinesterase inhibitors. J Chem Inf Model 2015;55(8):1521-8.

43. Labbé CM, Rey J, Lagorce D, et al. MTiOpenScreen: a web server for structure-based virtual screening. Nucleic Acids Res 2015;43(W1):W448-54.

44. Tsai T-Y, Chang K-W, Chen CY-C. iScreen: world's first cloud-computing web server for virtual screening and de novo drug design based on TCM database@ Taiwan. J Comput Aided Mol Des 2011;25(6):525-31.

45. Guedes IA, Krempser E, Dardenne LE. DockThor 2.0: a free web server for protein-ligand virtual screening. XIX SBQTSimpósio Brasileiro de Química Teórica 2017.

46. Annamala MK, Inampudi KK, Guruprasad L. Docking of phosphonate and trehalose analog inhibitors into M. tuberculosis mycolyltransferase Ag85C: comparison of the two scoring fitness functions GoldScore and ChemScore, in the GOLD software. Bioinformation 2007;1(9):339.

47. Schellhammer I, Rarey M. FlexX-scan: fast, structure-based virtual screening. PROTEINS 2004;57(3):504-17.

48. LeCun Y, Bengio Y, Hinton G. Deep learning. Nature 2015;521(7553):436-44.

49. Ji Q Sun Y, Gao J, et al. Nonlinear subspace clustering via adaptive graph regularized autoencoder. IEEE Access 2019;7:74122-33.

50. Xie $\mathrm{Y}$, Gong $\mathrm{M}$, Qin $\mathrm{AK}$, et al. TPNE: topology preserving network embedding. Inform Sci 2019;504:20-31.

51. Zhao J, Jiao L. Fast sparse deep neural networks: theory and performance analysis. IEEE Access 2019;7:74040-55.

52. Wold S, Esbensen K, Geladi P. Principal component analysis. Chemom Intel Lab Syst 1987;2(1-3):37-52.

53. Lee DD, Seung HS. Learning the parts of objects by non-negative matrix factorization. Nature 1999;401(6755): 788.

54. Roweis ST, Saul LK. Nonlinear dimensionality reduction by locally linear embedding. Science 2000;290(5500):2323-6.

55. Ng AY, Jordan MI, Weiss Y. On spectral clustering: Analysis and an algorithm. In: Advances in Neural Information Processing Systems, 2002;849-856. https://dl.acm.org/ doi/10.5555/2980539.2980649.

56. MacParland SA, Liu JC, Ma XZ, et al. Single cell RNA sequencing of human liver reveals distinct intrahepatic macrophage populations. Nat Commun 2018;9(1):1-21.

57. Kiselev VY, Kirschner K, Schaub MT, et al. SC3: consensus clustering of single-cell RNA-seq data. Nat Methods 2017;14(5):483-6. 
58. Eraslan G, Avsec Ž, Gagneur J, et al. Deep learning: new computational modelling techniques for genomics. Nature Reviews Genetics 2019;20(7):389-403. https://doi.org/10.1038/ s41576-019-0122-6.

59. Tian T, Wan J, Song Q et al. Clustering single-cell RNA-seq data with a model-based deep learning approach. Nature Machine Intelligence 2019;1(4):191-8.

60. Zhavoronkov A, Ivanenkov YA, Aliper A, et al. Deep learning enables rapid identification of potent DDR1 kinase inhibitors. Nat Biotechnol 2019;37(9):1038-40.

61. Dimitri GM, Lió P. DrugClust: a machine learning approach for drugs side effects prediction. Comput Biol Chem 2017;68:204-10.

62. Shoombuatong W, Schaduangrat N, Pratiwi R, et al. THPep: a machine learning-based approach for predicting tumor homing peptides. Comput Biol Chem 2019;80:441-51.

63. Alsenan S, Al-Turaiki I, Hafez A. A recurrent neural network model to predict blood-brain barrier permeability. Comput Biol Chem 2020;89:107377.

64. Gertrudes J, Maltarollo VG, Silva RA, et al. Machine learning techniques and drug design. Curr Med Chem 2012;19(25):4289-97.

65. Serafim MSM, dos Santos Júnior VS, Gertrudes JC, et al. Machine learning techniques applied to the drug design and discovery of new antivirals: a brief look over the past decade. Expert Opin Drug Discovery 2021;16(9):961-75.

66. Burbidge $\mathrm{R}$, Trotter $\mathrm{M}$, Buxton $\mathrm{B}$, et al. Drug design by machine learning: support vector machines for pharmaceutical data analysis. Comput Chem 2001;26(1):5-14.

67. Meng Z, Xia K. Persistent spectral-based machine learning (PerSpect ML) for protein-ligand binding affinity prediction. Science Advances 2021;7(19):eabc5329. https://doi.o rg/10.1126/sciadv.abc5329. February 11, 2020; preprint: not peer reviewed.

68. Loucera C, Esteban-Medina M, Rian K, et al. Drug repurposing for COVID-19 using machine learning and mechanistic models of signal transduction circuits related to SARS-CoV2 infection. Signal Transduct Target Ther 2020;5(1):1-3.

69. Islam M, Poly TN, Alsinglawi B, et al. A state-of-the-art survey on artificial intelligence to fight COVID-19.J Clin Med 2021;10(9):1961.

70. Lucchetta M, Pellegrini M. Drug repositioning by merging active subnetworks validated in cancer and COVID19. medRxiv 2021. May 18, 2021. https://doi.org/10.1101/2021. 05.13.21257140 preprint: not peer reviewed.

71. Kim S, Chen J, Cheng T, et al. PubChem in 2021: new data content and improved web interfaces. Nucleic Acids Res 2021;49(D1):D1388-95.

72. Gaulton A, Bellis LJ, Bento AP, et al. ChEMBL: a large-scale bioactivity database for drug discovery. Nucleic Acids Res 2012;40(D1):D1100-7.

73. Wishart DS, Knox C, Guo AC, et al. DrugBank: a knowledgebase for drugs, drug actions and drug targets. Nucleic Acids Res 2008;36(suppl_1):D901-6.

74. Siramshetty VB, Eckert OA, Gohlke BO, et al. SuperDRUG2: a one stop resource for approved/marketed drugs. Nucleic Acids Res 2018;46(D1):D1137-43.

75. Pihan E, Colliandre L, Guichou JF, et al. E-Drug3D: 3D structure collections dedicated to drug repurposing and fragment-based drug design. Bioinformatics 2012;28(11): 1540-1.

76. Liu $\mathrm{T}$, Lin $\mathrm{Y}$, Wen $\mathrm{X}$, et al. BindingDB: a web-accessible database of experimentally determined protein-ligand binding affinities. Nucleic Acids Res 2007;35(Database):D198201.

77. Stark C, Breitkreutz BJ, Reguly T, et al. BioGRID: a general repository for interaction datasets. Nucleic Acids Res 2006;34(90001):D535-9.

78. Wishart DS, Tzur D, Knox C, et al. HMDB: the human metabolome database. Nucleic Acids Res 2007; 35(Database):D521-6.

79. Frolkis A, Knox C, Lim E, et al. SMPDB: the small molecule pathway database. Nucleic Acids Res 2010;38(suppl_1): D480-7.

80. Svoboda DL, Saddler T, Auerbach SS. An overview of National Toxicology Program's Toxicogenomic applications: DrugMatrix and ToxFX. Adv Comput Toxicol 2019;30:141-57.

81. Kuhn M, Letunic I, Jensen LJ, et al. The SIDER database of drugs and side effects. Nucleic Acids Res 2016;44(D1): D1075-9.

82. Tasneem A, Aberle L, Ananth $\mathrm{H}$, et al. The database for aggregate analysis of ClinicalTrials. Gov (AACT) and subsequent regrouping by clinical specialty. PLoS One 2012;7(3):e33677.

83. Hewett $\mathrm{M}$, Oliver $\mathrm{DE}$, Rubin DL, et al. PharmGKB: the pharmacogenetics knowledge base. Nucleic acids research 2002;30(1):163-65. https://doi.org/10.1093/nar/30.1.163.

84. Oughtred R, Stark C, Breitkreutz BJ, et al. The BioGRID interaction database: 2019 update. Nucleic Acids Res 2019;47(D1):D529-41.

85. Liu X, Wang XJ. Potential inhibitors against 2019-nCoV coronavirus $\mathrm{M}$ protease from clinically approved medicines. $J$ Genet Genomics 2020;47(2):119-21.

86. Jin $\mathrm{Z}$, du X, Xu Y, et al. Structure of Mpro from SARS-CoV-2 and discovery of its inhibitors. Nature 2020;582(7811): 289-93.

87. Singh S, Florez H. Coronavirus disease 2019 drug discovery through molecular docking. F1000Res 2020;9:502.

88. Yu R, Chen L, Lan R, et al. Computational screening of antagonists against the SARS-CoV-2 (COVID-19) coronavirus by molecular docking. Int $J$ Antimicrob Agents 2020;56(2): 106012.

89. Singh R, Gautam A, Chandel S, et al. Protease inhibitory effect of natural polyphenolic compounds on SARS-CoV-2: an in silico study. Molecules 2020;25(20):4604.

90. Sencanski M, Perovic V, Pajovic SB, et al. Drug repurposing for candidate SARS-CoV-2 main protease inhibitors by a novel in silico method. Molecules 2020;25(17):3830.

91. Rakib A, Paul A, Chy MNU, et al. Biochemical and computational approach of selected phytocompounds from Tinospora crispa in the management of COVID-19. Molecules 2020;25(17):3936.

92. Kumar A, Choudhir G, Shukla SK, et al. Identification of phytochemical inhibitors against main protease of COVID19 using molecular modeling approaches. J Biomol Struct Dyn 2021;39(10):3760-70.

93. Islam R, Parves MR, Paul AS, et al. A molecular modeling approach to identify effective antiviral phytochemicals against the main protease of SARSCoV-2. J Biomol Struct Dyn 2021;39(9):3213-24. https://doi.o $\mathrm{rg} / 10.1080 / 07391102.2020 .1761883$.

94. Ibrahim MAA, Abdeljawaad KAA, Abdelrahman AHM, et al. Natural-like products as potential SARS-CoV-2 M(pro) inhibitors: in-silico drug discovery. J Biomol Struct Dyn 2021;39(15):5722-34. 
95. Han Y, Král P. Computational design of ACE2-based peptide inhibitors of SARS-CoV-2. ACS Nano 2020;14(4): 5143-7.

96. Deeks HM, Walters RK, Barnoud J, et al. Interactive molecular dynamics in virtual reality is an effective tool for flexible substrate and inhibitor docking to the SARS-CoV-2 main protease. J Chem Inf Model 2020;60(12):5803-14.

97. Das S, Sarmah S, Lyndem S, et al. An investigation into the identification of potential inhibitors of SARSCoV-2 main protease using molecular docking study. J Biomol Struct Dyn 2021;39(9):3347-57. https://doi.o rg/10.1080/07391102.2020.1763201.

98. Chakraborti S, Bheemireddy S, Srinivasan N. Repurposing drugs against the main protease of SARS-CoV-2: mechanism-based insights supported by available laboratory and clinical data. Mol Omics 2020;16(5):474-91.

99. al-Sehemi AG, Pannipara M, Parulekar RS, et al. Potential of NO donor furoxan as SARS-CoV-2 main protease (M(pro)) inhibitors: in silico analysis. J Biomol Struct Dyn 2021;39(15):5804-18.

100. Yang $Y$, Zhu Z, Wang X, et al. Ligand-based approach for predicting drug targets and for virtual screening against COVID-19. Brief Bioinform 2021;22(2):1053-64.

101. Aanouz I, Belhassan A, el-Khatabi K, et al. Moroccan medicinal plants as inhibitors against SARS-CoV-2 main protease: computational investigations. J Biomol Struct Dyn 2021;39(8):2971-9.

102. Alamri MA, Tahir ul Qamar M, Mirza MU, et al. Pharmacoinformatics and molecular dynamics simulation studies reveal potential covalent and FDA-approved inhibitors of SARS-CoV-2 main protease 3CL(pro). J Biomol Struct Dyn 2021;39(13):4936-48.

103. Abel R, Paredes Ramos $M$, Chen $Q$ et al. Computational prediction of potential inhibitors of the main protease of SARS-CoV-2. Front Chem 2020;8:590263.

104. Banerjee P, Erehman J, Gohlke BO, et al. Super natural II-a database of natural products. Nucleic Acids Res 2015;43(D1):D935-9.

105. He M, Yan X, Zhou J, et al. Traditional Chinese medicine database and application on the web. J Chem Inf Comput Sci 2001;41(2):273-7.

106. Kim, J.-Y., Kim, Dong-Wook, Kim, Sun-Woo et al. Diversity of compounds in Korea Chemical Bank. in Proceedings of the PSK Conference. 2002. The Pharmaceutical Society of Korea, 189.2-189.

107. Baby K, Maity S, Mehta CH, et al. Targeting SARS-CoV-2 main protease: a computational drug repurposing study. Arch Med Res 2021;52(1):38-47.

108. Mishra SS, Ranjan S, Sharma CS, et al. Computational investigation of potential inhibitors of novel coronavirus 2019 through structure-based virtual screening, molecular dynamics and density functional theory studies. J Biomol Struct Dyn 2021;39(12):4449-61.

109. Hage-Melim L, Federico LB, de Oliveira NKS, et al. Virtual screening, ADME/Tox predictions and the drug repurposing concept for future use of old drugs against the COVID-19. Life Sci 2020;256:117963.

110. Fischer A, Sellner M, Neranjan S, et al. Potential inhibitors for novel coronavirus protease identified by virtual screening of 606 million compounds. Int J Mol Sci 2020;21(10):3626.

111. Rahman MM, Saha T, Islam KJ, et al. Virtual screening, molecular dynamics and structure-activity relationship studies to identify potent approved drugs for Covid-19 treatment. J Biomol Struct Dyn 2021;39(16):6231-41.
112. Gentile D, Patamia V, Scala A, et al. Putative inhibitors of SARS-CoV-2 main protease from a library of marine natural products: a virtual screening and molecular Modeling study. Mar Drugs 2020;18(4):225.

113. Arun KG, Sharanya CS, Abhithaj J, et al. Drug repurposing against SARS-CoV-2 using E-pharmacophore based virtual screening, molecular docking and molecular dynamics with main protease as the target. J Biomol Struct Dyn 2021;39(13):4647-58.

114. Culletta G, Gulotta MR, Perricone U, et al. Exploring the SARS-CoV-2 proteome in the search of potential inhibitors via structure-based pharmacophore modeling/docking approach. Comput Secur 2020;8(3):77.

115. Eleftheriou P, Amanatidou D, Petrou A, et al. In silico evaluation of the effectivity of approved protease inhibitors against the main protease of the novel SARS-CoV-2 virus. Molecules 2020;25(11):2529.

116. Ishola AA, Adedirin O, Joshi $\mathrm{T}$, et al. QSAR modeling and Pharmacoinformatics of SARS coronavirus 3C-like protease inhibitors. Comput Biol Med 2021;134:104483.

117. Kumar V, Roy K. Development of a simple, interpretable and easily transferable QSAR model for quick screening antiviral databases in search of novel 3C-like protease (3CLpro) enzyme inhibitors against SARS-CoV diseases. SAR QSAR Environ Res 2020;31(7):511-26.

118. Gogoi N, Chowdhury P, Goswami AK, et al. Computational guided identification of a citrus flavonoid as potential inhibitor of SARS-CoV-2 main protease. Mol Divers 2021;25(3):1745-59.

119. Ngo ST, Quynh Anh Pham N, Thi le L, et al. Computational determination of potential inhibitors of SARS-CoV-2 main protease. J Chem Inf Model 2020;60(12):5771-80.

120. Andrianov AM, Kornoushenko YV, Karpenko AD, et al. Computational discovery of small drug-like compounds as potential inhibitors of SARS-CoV-2 main protease. J Biomol Struct Dyn 2021;39(15):5779-91.

121. Huang $\mathrm{R}, \mathrm{Xu} \mathrm{M}, \mathrm{Zhu} \mathrm{H}$, et al. Biological activity-based modeling identifies antiviral leads against SARS-CoV-2. Nat Biotechnol 2021;39(6):747-53.

122. Nayarisseri A, Khandelwal R, Madhavi M, et al. Shape-based machine learning models for the potential novel COVID19 protease inhibitors assisted by molecular dynamics simulation. Curr Top Med Chem 2020;20(24):2146-67.

123. Gimeno A, Mestres-Truyol J, Ojeda-Montes MJ, et al. Prediction of novel inhibitors of the main protease (M-pro) of SARS-CoV-2 through consensus docking and drug reposition. Int J Mol Sci 2020;21(11):3793.

124. OEChem TK. OpenEye Scientific Software. Software (Inc.). NM, USA: Santa Fe, 2012.

125. Battisti V, Wieder O, Garon A, et al. A computational approach to identify potential novel inhibitors against the coronavirus SARS-CoV-2. Mol Inform 2020;39(10):e2000090.

126. Ivanenkov $\mathrm{Y}$, Aladinskiy $\mathrm{V}$, Zhebrak A, et al. Potential COVID-2019 3C-like protease inhibitors designed using generative deep learning approaches. ChemRxiv Preprint posted online on February 2020;11.

127. Beck BR, Shin B, Choi Y, et al. Predicting commercially available antiviral drugs that may act on the novel coronavirus (SARS-CoV-2) through a drug-target interaction deep learning model. Comput Struct Biotechnol J 2020;18: 784-90.

128. Bung NAK, Krishnan SR, Bulusu G, et al. De novodesign of new chemical entities for SARS-CoV-2 using artificial intelligence. Future Med Chem 2021;13(6):575-85. 
129. Zhang H, Saravanan KM, Yang Y, et al. Deep learning based drug screening for novel coronavirus 2019-nCov. Interdiscip Sci 2020;12(3):368-76.

130. Wang M-Y, Zhao R, Gao LJ, et al. SARS-CoV-2: structure, biology, and structure-based therapeutics development. Front Cell Infect Microbiol 2020;10:587269.

131. Jiang YP, Zhao XX, Lv HQ et al. Drug screening and development from the affinity of $\mathrm{S}$ protein of new coronavirus with ACE2. Eur J Clin Microbiol Infect Dis 2021;40(4): 715-23.

132. Faria S, Teleschi JG. Computational search for drug repurposing to identify potential inhibitors against SARS-COV2 using molecular docking, QTAIM and IQA methods in viral spike protein - human ACE2 interface. J Mol Struct 2021;1232:130076.

133. Cubuk H, OzbIl M. Comparison of clinically approved molecules on SARS-CoV-2 drug target proteins: a molecular docking study. Turk J Chem 2021;45(1):35-41.

134. Unni S, Aouti S, Thiyagarajan S, et al. Identification of a repurposed drug as an inhibitor of spike protein of human coronavirus SARS-CoV- 2 by computational methods. J Biosci 2020;45(1):1-20.

135. Choudhary S, Malik YS, Tomar S. Identification of SARSCoV-2 cell entry inhibitors by drug repurposing using in silico structure-based virtual screening approach. Front Immunol 2020;11:1664.

136. Dong S, Sun J, Mao Z, et al. A guideline for homology modeling of the proteins from newly discovered betacoronavirus, 2019 novel coronavirus (2019-nCoV). J Med Virol 2020;92(9):1542-8.

137. Borkotoky S, Banerjee M. A computational prediction of SARS-CoV-2 structural protein inhibitors fromAzadirachta indica(neem). J Biomol Struct Dyn 2021;39(11):4111-21.

138. Aftab SO, Ghouri MZ, Masood MU, et al. Analysis of SARSCoV-2 RNA-dependent RNA polymerase as a potential therapeutic drug target using a computational approach. $J$ Transl Med 2020;18(1):275.

139. Pokhrel R, Chapagain P, Siltberg-Liberles J. Potential RNA-dependent RNA polymerase inhibitors as prospective therapeutics against SARS-CoV-2. J Med Microbiol 2020;69(6):864-73.

140. Wu C, Liu Y, Yang Y, et al. Analysis of therapeutic targets for SARS-CoV-2 and discovery of potential drugs by computational methods. Acta Pharmaceutica Sinica B 2020;10(5): 766-88.

141. Borgio JF, Alsuwat HS, al Otaibi WM, et al. State-of-theart tools unveil potent drug targets amongst clinically approved drugs to inhibit helicase in SARS-CoV-2. Arch Med Sci 2020;16(3):508-18.

142. Mirza MU, Froeyen M. Structural elucidation of SARSCoV-2 vital proteins: computational methods reveal potential drug candidates against main protease, Nsp12 polymerase and Nsp13 helicase. J Pharm Anal 2020;10(4): 320-8.

143. Iftikhar H, Ali HN, Farooq S, et al. Identification of potential inhibitors of three key enzymes of SARS-CoV2 using computational approach. Comput Biol Med 2020;122: 103848.

144. Bortz E, Westera L, Maamary J, et al. Host- and strainspecific regulation of influenza virus polymerase activity by interacting cellular proteins. MBio 2011;2(4): e00151-11.

145. Grady SL, Hwang J, Vastag L, et al. Herpes simplex virus 1 infection activates poly (ADP-ribose) polymerase and triggers the degradation of poly (ADP-ribose) glycohydrolase. $J$ Virol 2012;86(15):8259-68.

146. Liu L, Lear Z, Hughes DJ, et al. Resolution of the cellular proteome of the nucleocapsid protein from a highly pathogenic isolate of porcine reproductive and respiratory syndrome virus identifies PARP-1 as a cellular target whose interaction is critical for virus biology. Vet Microbiol 2015;176(1-2):109-19.

147. Ge Y, Tian T, Huang S, et al. A data-driven drug repositioning framework discovered a potential therapeutic agent targeting COVID-19. BioRxiv 2020.

148. Motwalli O, Alazmi M. Analysis of natural compounds against the activity of SARS-CoV-2 NSP15 protein towards an effective treatment against COVID-19: a theoretical and computational biology approach. J Mol Model 2021;27(6): 160.

149. Devaurs D, Antunes DA, Kavraki LE. Computational analysis of complement inhibitor compstatin using molecular dynamics. J Mol Model 2020;26(9):231.

150. Selvaraj C, Dinesh DC, Panwar U, et al. Structure-based virtual screening and molecular dynamics simulation of SARS-CoV-2 guanine-N7 methyltransferase (nsp14) for identifying antiviral inhibitors against COVID-19. J Biomol Struct Dyn 2021;39(13):4582-93.

151. Chandra A, Gurjar V, Qamar I, et al. Identification of potential inhibitors of SARS-COV-2 endoribonuclease (EndoU) from FDA approved drugs: a drug repurposing approach to find therapeutics for COVID-19. J Biomol Struct Dyn 2021;39(12):4201-11.

152. Gossen J, Albani S, Hanke A, et al. A blueprint for high affinity SARS-CoV-2 Mpro inhibitors from activitybased compound library screening guided by analysis of protein dynamics. ACS Pharmacol Translat Sci 2021;4(3): 1079-95.

153. Ugurel OM, Mutlu O, Sariyer E, et al. Evaluation of the potency of FDA-approved drugs on wild type and mutant SARS-CoV-2 helicase (Nsp13). Int J Biol Macromol 2020;163:1687-96. 